\title{
Are T1 values to characterize myocardial tissue equivalent between various sequences: comparison of MOLLI, shMOLLI, 3'5-MOLLI and SASHA
}

Valentina O Puntmann ${ }^{1 *}$, Tobias Voigt ${ }^{3}$, Darius Dabir ${ }^{1}$, Toby Rogers ${ }^{1}$, Tobias Schaeffter ${ }^{2}$, Eike Nagel ${ }^{3}$

From 16th Annual SCMR Scientific Sessions

San Francisco, CA, USA. 31 January - 3 February 2013

\section{Background}

Classical modified Look-Locker sequence (MOLLI) can induce a long breath-hold and is prone to cardiac and respiratory motion. Several shorter sequences based on inversion (3'5MOLLI, shMOLLI) and saturation recovery (SASHA) of longitudinal relaxation have been proposed for derivation of $\mathrm{T} 1$ values or calculation of extracellular volume fraction or lambdas. Despite the validation in $\mathrm{T} 1$ gel phantoms, it has not been determined whether these novel sequences provide equivalent information on $\mathrm{T} 1$ when performed within the same individual.

\section{Methods}

Twenty-three subjects underwent T1 mapping in a midventricular equatorial short axis slice using above sequences on $3 \mathrm{~T}$ clinical scanner prior and after gadolinium contrast $(0.2 \mathrm{mmol} / \mathrm{kg})$ administration. The images were analyzed using PRIDE tool with in-built automated motion correction. ROIs were drawn conservatively within the septal and lateral myocardium and the blood pool. Comparison of the native T1 values and lambdas were performed and expressed as percentage of mean difference from the values obtained with goldstandard MOLLI sequence.

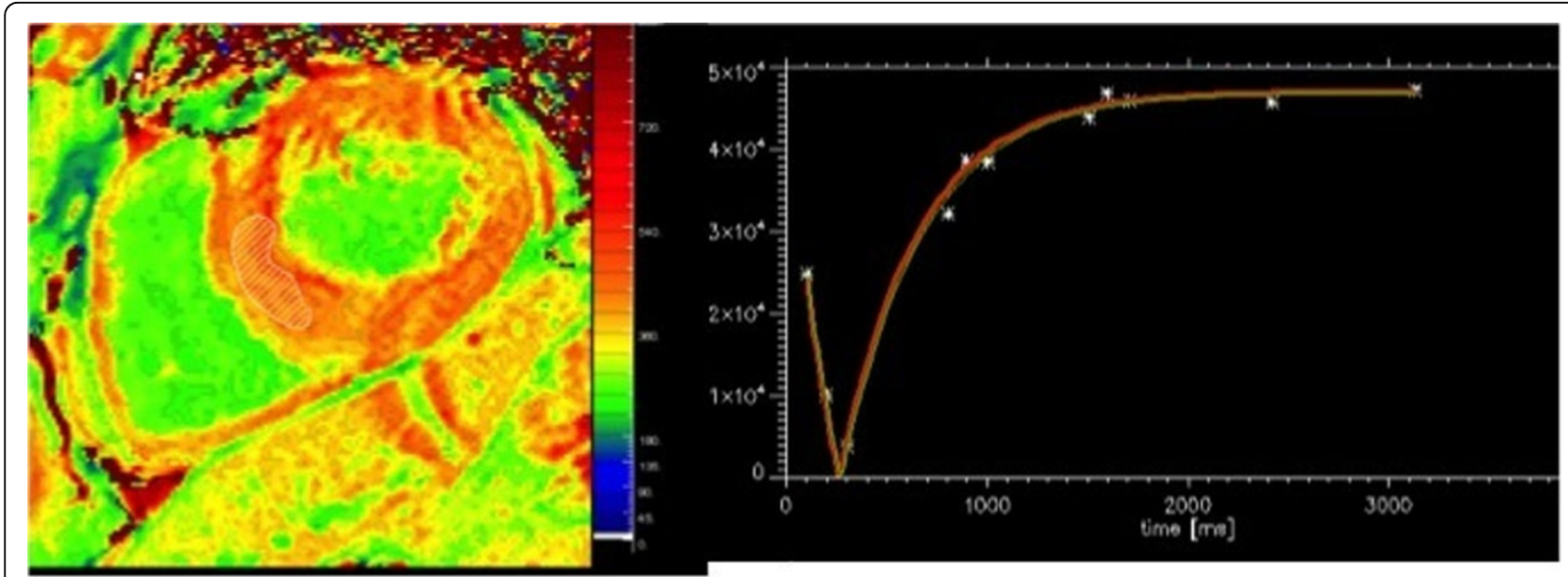

Figure 1 Postcontrast 3'5'MOLLI with inversion-recovery fitting curve.

${ }^{1}$ Cardiovascular Imaging, King's College London, London, UK

Full list of author information is available at the end of the article 


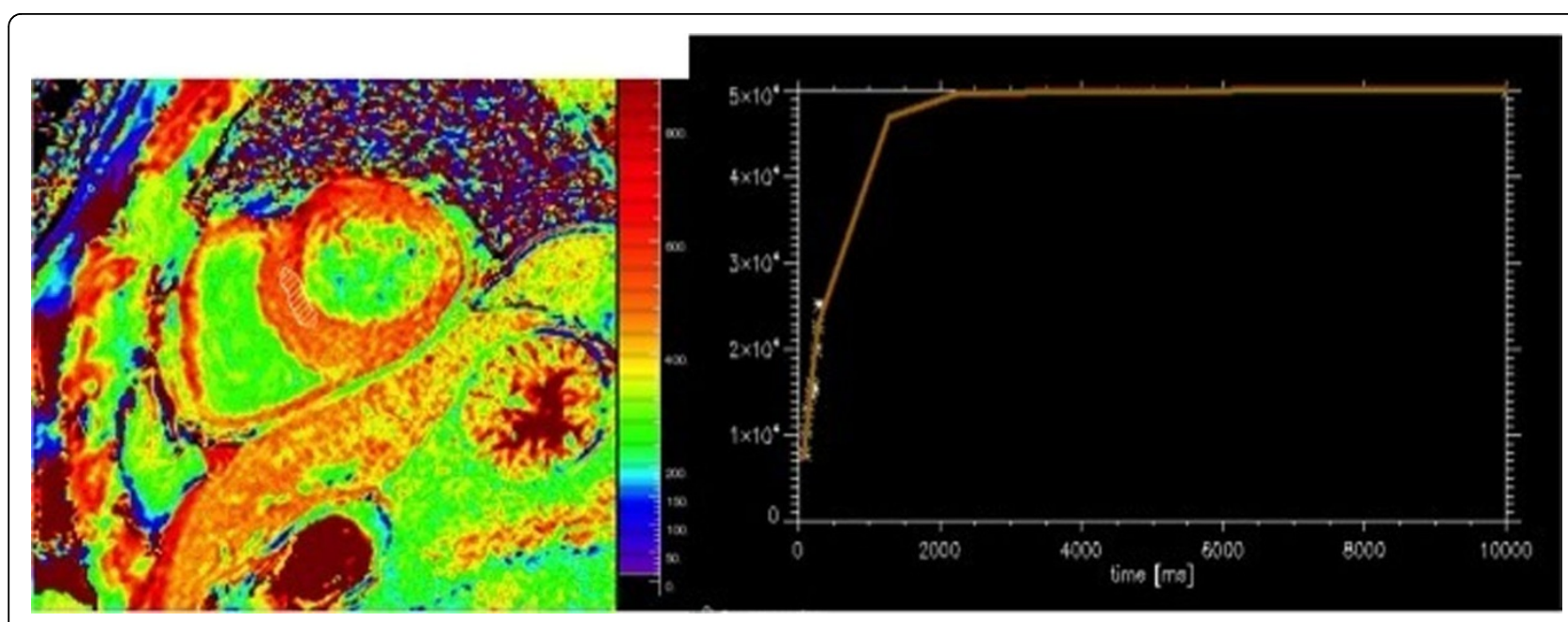

Figure 2 Postcontrast SASHA map with saturation recovery fitting curve.

\section{Results}

3'5MOLLI shows the nearest approximation to MOLLI derived values with an underestimation of values in native myocardium by $1.2 \%$ and lambdas by $11 \%$. T 1 values obtained with SASHA were overestimated by $17 \%$, and lambdas by $29 \%$, whereas shMOLLI led to an underestimation of $\mathrm{T} 1$ values by $13 \%$ and lambdas by $22 \%$.

\section{Conclusions}

We demonstrate that 3'5'MOLLI provides near identical $\mathrm{T} 1$ values and its derivatives.

We propose that 3'5'MOLLI is the optimal 'shortened' sequence for clinical derivation of $\mathrm{T} 1$ values.

\section{Funding}

NIHR

\section{Author details}

${ }^{1}$ Cardiovascular Imaging, King's College London, London, UK. ${ }^{2}$ Medical Physics and Bioengineering, King's College London, London, UK. ${ }^{3}$ Philips Innovative Technologies, London, London, UK.

Published: 30 January 2013

doi:10.1186/1532-429X-15-S1-E18

Cite this article as: Puntmann et al:: Are T1 values to characterize myocardial tissue equivalent between various sequences: comparison of MOLLI, shMOLLI, 3'5-MOLLI and SASHA. Journal of Cardiovascular Magnetic Resonance 2013 15(Suppl 1):E18.

\section{Submit your next manuscript to BioMed Central} and take full advantage of:

- Convenient online submission

- Thorough peer review

- No space constraints or color figure charges

- Immediate publication on acceptance

- Inclusion in PubMed, CAS, Scopus and Google Scholar

- Research which is freely available for redistribution
Biomed Central 